\title{
FORMULATION OF EPOXY BASED ANTICORROSION COATING INCORPORATED WITH BIOCOMPATIBLE NANO $\mathrm{TiO}_{2}$-PEDOT:PSS HYBRID COMPOSITE
}

\author{
NURUL AZIMAH MAHAMAD AZIZ ${ }^{1}$, MOHD SABRI MOHD GHAZALI*2,3,4,5, WAN RAFIZAH \\ WAN ABDULLAH ${ }^{1,5}$, WAN MOHD NORSANI WAN NIK ${ }^{1}$, NURUL AIN ABDUL RAHIM ${ }^{2}$, \\ NURUL HUDA ABD KADIR ${ }^{2}$, NUR SYAKIRAH MAHAMAD AZIZ ${ }^{2}$, NOOR ANIZA HARUN ${ }^{2}$ \\ MOHD ZUL HELMI ROZAINI ${ }^{6,7}$ AND WAN MOHAMAD IKHMAL WAN KAMARUZZAMAN ${ }^{2}$
}

${ }^{1}$ Faculty of Ocean Engineering Technology and Informatics, ${ }^{2}$ Faculty of Science and Marine Environement, ${ }^{3}$ Advanced Nano Materials (ANoMa) Research Group, School of Fundamental Science, ${ }^{4}$ Institute of Tropical Biodiversity and Sustainable Development, ${ }^{6}$ Institute of Marine Biotechnology, ${ }^{7}$ Faculty of Fisheries and Food Science, Universiti Malaysia Terengganu, 21030 Kuala Nerus, Terengganu, Malaysia. ${ }^{5}$ Materials Synthesis \& Characterization Laboratory (MSCL), Institute of Advanced Technology, Universiti Putra Malaysia, 43400 UPM Serdang, Selangor Darul Ehsan, Malaysia.

*Corresponding author: mohdsabri@umt.edu.my

Submitted final draft: 27 July $2019 \quad$ Accepted: 16 December $2019 \quad$ http://doi.org/10.46754/jssm.2020.07.002

\begin{abstract}
Anticorrosion coatings are a common means of corrosion control. For the past few years, one of the more widely used anticorrosion coatings was chromium based. However, chromium was found to be highly toxic and its use has been discontinued. An epoxy-based coating is formulated by incorporating a biocompatible hybrid composite of inorganic nano titanium dioxide $\left(\mathrm{TiO}_{2}\right)$ and organic poly (3, 4-ethylenedioxythiophene) polystyrene sulfonate (PEDOT:PSS) in an epoxy matrix. The nanocomposite was mixed at a 3:1 ratio and dispersed in the epoxy matrix at varying weight percentage (1-5 wt.\%). The toxicity effect of the nano $\mathrm{TiO}_{2}$-PEDOT:PSS composite was evaluated via assay of fibroblast cells viability. The formulated coating was analysed for corrosion resistance using potentiodynamic polarization (PP). The cytotoxicity assay verified that this nanocomposite is indeed non-toxic with the cell viability percentage as high as $178 \%$ and $159 \%$ after 24 and 48 hours of treatment, respectively. The PP analysis showed that the coating containing 3 wt.\% nanocomposite has the most viable anticorrosion properties, with $E_{\text {corr }}$ value at $-0.32467 \mathrm{~V}, I_{\text {corr }}$ value at $0.534 \mu \mathrm{A} / \mathrm{cm}^{2}$ and the lowest corrosion rate at $0.006204 \mathrm{~mm} / \mathrm{yr}$. The results showed that the nanocomposite additive is biocompatible and is efficient as anticorrosive additive in coatings.
\end{abstract}

Keywords: Anticorrosion coating, sustainable coating, titanium dioxide, PEDOT:PSS, hybrid nanocomposite.

\section{Introduction}

Corrosion is one of the most concerning problems in the world, since it has caused thousands of billions of losses annually (Koch et al., 2016). Hence, several corrosion control methods have been employed to address this problem, such as protective coatings and cathodic protection (sacrificial anode) (Safiuddin, 2006). Anticorrosion coatings are a viable means of corrosion control as they promote efficient use of materials and cost reduction since almost all engineering materials can be utilised as reinforcement coating (Aliofkhazraei, 2014; Ikhmal et al., 2018; Maria et al., 2018). Even though there are all kinds of different anticorrosion coatings, some of the most widely used coatings up to a few years ago, were chromium based. This is due to them being economically feasible, as well as their efficiency in corrosion control. Unfortunately, chromium has been found to be toxic and its use has been discontinued in several countries (Vernhes et al., 2013).

$\mathrm{TiO}_{2}$ is a material that can be found in sunscreens and other beauty products. In fact, several toxicity tests on this substance have verified that $\mathrm{TiO}_{2}$ has low toxicity and is generally not harmful to our body or the environment (Fabian et al., 2008). Meanwhile, PEDOT:PSS is gaining recognition in the 
medical field, apart from its established use in electronic and optical devices. This conducting polymer has been reported to be used in human bone studies (Yazdimamaghani et al., 2015) as well as other medical applications (Hempel et al., 2017). Not only is PEDOT:PSS low in toxicity, it has also been claimed to stimulate cell growth (Gajendiran et al., 2017; Nur Ain et $a l ., 2018)$. Still, there are very few studies on the cytotoxicity profile of the nanoTiO ${ }_{2}$-PEDOT:PSS composite, or even nanocomposites in general (Nurul Azimah et al., 2017).

Apart from that, $\mathrm{TiO}_{2}$ and PEDOT:PSS have been used in coatings as additives and have been proven to impart excellent anticorrosion properties. The use of PEDOT:PSS as anticorrosive additive in epoxy coating was shown to be able to protect hull steel from corrosion even in harsh marine environment (Hou et al., 2013). Plus, $\mathrm{TiO}_{2}$ combined with other conducting polymers as anticorrosive additives has yielded positive results in corrosion control (Ates \& Topkaya, 2015).

These findings indicate that $\mathrm{TiO}_{2}$ and PEDOT:PSS are biocompatible materials that can be used safely as additives in coatings not only for their sustainability, but also for their excellent corrosion protection properties. Thus, these substances are used in this study to formulate an efficient anticorrosion coating with low threats to humans, aquatics life and the environment.

\section{Materials and Methods}

\section{Reagents and Materials}

PEDOT:PSS (2.8 wt.\% dispersion in $\mathrm{H}_{2} \mathrm{O}$ ) and $\mathrm{TiO}_{2}$ nanoparticles $(<25 \mathrm{~nm}$, anatase) were purchased from Sigma Aldrich. Epoxy resin and polyamide hardener were acquired as a set from Quickmount $^{\mathrm{TM}}$. The coating was applied on stainless steel 316L substrates, with composition as displayed in Table 1. The substrate was obtained from CG Tradeware and was cut into $2.5 \mathrm{~cm} \times 2.5 \mathrm{~cm} \times 0.15 \mathrm{~cm}$ plates before coating. The fibroblast cells and AlamarBlue ${ }^{\mathrm{TM}}$ reagent were acquired from ATCC while the 96 well plates were from Nunc.
Table 1: Composition of Stainless Steel 316L.

\begin{tabular}{cc}
\hline Element & Stainless Steel 316L (\%) \\
\hline $\mathbf{C}$ & 0.03 max. \\
$\mathbf{M n}$ & 2.00 max. \\
$\mathbf{P}$ & 0.045 max. \\
$\mathbf{S}$ & 0.03 max. \\
$\mathbf{S i}$ & 0.75 max. \\
$\mathbf{C r}$ & $16.00-18.00$ \\
$\mathbf{N i}$ & $10.00-14.00$ \\
$\mathbf{M o}$ & $2.00-3.00$ \\
$\mathbf{N}$ & 0.10 max. \\
$\mathbf{F e}$ & Balance \\
\hline
\end{tabular}

\section{Preparation of Hybrid Nano $\mathrm{TiO}_{2}-\mathrm{PEDOT}$ :PSS Composite}

The nanocomposite was prepared prior to addition to the epoxy matrix. PEDOT:PSS and $\mathrm{TiO}_{2}$ nanoparticles were mixed at a 3:1 ratio and stirred mechanically for 1 hour using a magnetic stirrer at a speed of $1000 \mathrm{rpm}$. The mixture was later sonicated in a bath sonicator for up to an hour at temperature below $50^{\circ} \mathrm{C}$ to assure better interaction between the two components and to avoid clumping.

\section{Cytotoxicity Assay of the Nanocomposite}

The cytotoxicity assay was carried out on fibroblast cells using AlamarBlue ${ }^{\mathrm{TM}}$ technique. Firstly, the nanocomposite was prepared at different concentrations $(0.625 \%, 1.25 \%, 0.25 \%$ and $5 \%$ ) by diluting the pure nanocomposite compound with dimethyl sulfoxide (DMSO). It is important to dilute the compound first since in vitro cells cannot be treated directly with pure compound, due to the difference in reaction to exposure as compared to in vivo treatment. 10 $\mu \mathrm{L}$ of each concentrations of nanocomposite were added to cells in a 96 well plate. The control sample was treated with $10 \mu \mathrm{L}$ of blank DMSO. Afterwards, $10 \mu \mathrm{L}$ AlamarBlue ${ }^{\mathrm{TM}}$ reagent was added and the cells were incubated for up to 4 hours (Al-Nasiry et al., 2007). The cells were then measured at a wavelength of 570 $\mathrm{nm}$ for excitation and $585 \mathrm{~nm}$ for emission after 24 and 48 hours using a fluorescence microplate reader (Thermoscientific, USA). Cell viability was calculated after treatment of cells using Equation 1 (Hamid et al., 2004). 


$$
\text { Percentage of cell viability }=\frac{\text { Absorbance of treated cells }}{\text { Absorbance of untreated cells }} \times 100
$$

\section{Formulation of Coating}

The prepared nanocomposite was dispersed in epoxy resin at different loadings, from 1 wt. $\%$ to 5 wt.\%. The whole mixture was stirred mechanically for 4 hours at $1200 \mathrm{rpm}$ and then was subjected to sonication in a bath sonicator for 30 minutes, with temperature below $30^{\circ} \mathrm{C}$. The polyamide hardener was later added at a primer: hardener ratio of 10:1, and further stirred for 5 minutes, as per the manufacturer's instructions. The coating was applied using drop casting method onto stainless steel substrates that had been prepared according to procedural standards (ASTM International, 2004). The coated substrates were designated as EP1, EP2, EP3, EP4, and EP5, where EP refers to the epoxy coating, while the numbers indicate the amount of additives in the coating ( 1 to $5 \mathrm{wt} . \%$ ).

\section{Evaluation of Anticorrosion Properties}

The anticorrosion properties of the coatings were studied using potentiodynamic polarization (PP) method. This test was carried out using a three-electrode cell consisting of a working electrode, a reference electrode, and a counter electrode. The working electrode refers to the coated substrates with contact area of 1 $\mathrm{cm}^{2}$, the reference electrode is a saturated $\mathrm{Ag} /$ $\mathrm{AgCl}$ electrode, while the counter electrode is a glassy carbon electrode. The test was carried out at frequency range of $10 \mathrm{kHz}$ to $0.1 \mathrm{~Hz}$ at room temperature using $3.5 \% \mathrm{NaCl}$ solution as electrolyte. The acquired data were analysed using NOVA software. The bare stainless steel was also tested as a control sample. The parameters studied were $E_{\text {corr }}, I_{\text {corr }}$, and corrosion resistance, which were derived from the Tafel plot generated by the software.

\section{Results and Discussion}

Assessment of Cell Viability after Treatment with Nano $\mathrm{TiO}_{2}$-PEDOT:PSS Composite

The graph in Figure 1 shows similar trend between 24 and 48 hours cell viability, where the percentage of cell viability decreases with increment in nanocomposite concentrations. The highest cell viability after 24 hours was recorded at $178 \%$ at nanocomposite concentration of $1.25 \%$, while the concentration $2.5 \%$ had the highest cell viability at $159 \%$ after 48 hours. The lowest cell viability after 24 and 48 hours percentage is at treatment concentration of $5 \%$, with $108 \%$ and $102 \%$ cell viability respectively. These values notwithstanding, the cell viability results showed no induction of cell death whatsoever for all treatment concentrations even after 48 hours of exposure to the nanocomposite.

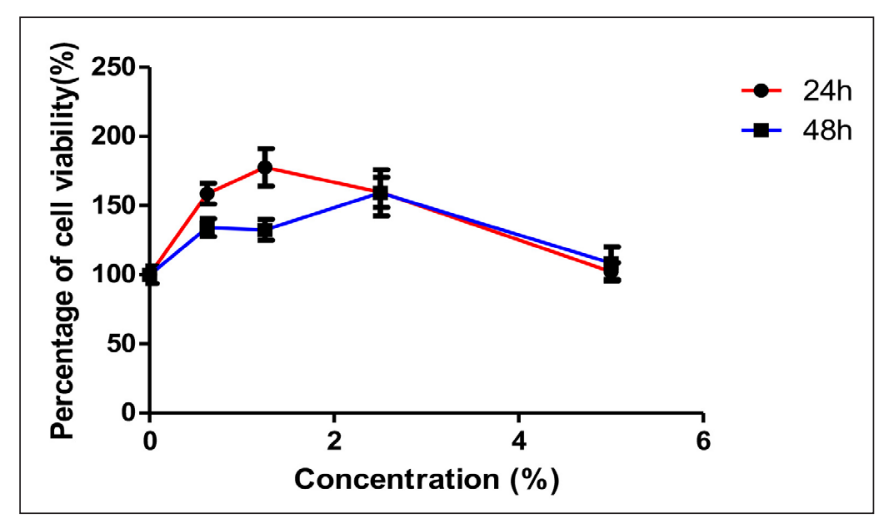

Figure 1: Cell viability (\%) of fibroblast cells for 24 and 48 hours after treatment with different concentrations of nano $\mathrm{TiO}_{2}$-PEDOT:PSS composite; $0 \%$ (control), $0.625 \%, 1.25 \%, 2.5 \%$, and $5 \%$ 
In fact, interestingly, looking at the reading of cell viability for concentrations $0.625 \%$, $1.25 \%, 0.25 \%$ and $5 \%$, it can be seen that cell viability percentages are higher than the control, which was treated with DMSO alone. This suggests that the nanocomposite compound did not cause major cell death nor did it inhibit cell growth, it actually induces the growth of cell. This might be due to the conductive properties of the nanocomposite compound, which stimulates cell growth (Gajendiran et al., 2017).

There are very few studies on the toxicity profile of nanocomposites. Nonetheless, according to these results, it is safe to say that the nano $\mathrm{TiO}_{2}$-PEDOT:PSS composite is nontoxic and safe for use as anticorrosive additives (Nurul Azimah et al., 2017).

\section{Anticorrosion Analysis of Formulated Coatings}

The mechanism of assessment of anticorrosion properties using potentiodynamic polarization (PP) is through an electrochemical analysis. Corrosion is an electrochemical process; hence it needs good current flow in order to occur. In this case, a low $I_{\text {corr }}$ value denotes impedance to current flow, which indicates good corrosion resistance. Table 2 outlines the results obtained while the Tafel plots are displayed in Figure 2. The readings of the coated substrates are compared to that of bare stainless steel to highlight the improvement in anticorrosion properties.

The comparison of all parameters of the coated substrates with the bare stainless steel in Table 2 shows that there is overall improvement

Table 2: Readings of $E_{\text {corr }}, I_{\text {corr }}$ and corrosion rate values of coated substrates and bare stainless steel 316L

\begin{tabular}{cccc}
\hline Material & $\boldsymbol{E}_{\text {corr }}(\mathbf{V})$ & $\boldsymbol{I}_{\text {corr }}\left(\boldsymbol{\mu \mathbf { A } / \mathbf { c m } ^ { 2 } )}\right.$ & $\begin{array}{c}\text { Corrosion rate } \\
(\mathbf{m m} / \mathbf{y r})\end{array}$ \\
\hline Stainless steel 316L & -0.26031 & 60.6 & 0.64403 \\
EP1 & -0.29283 & 6.50 & 0.07431 \\
EP2 & -0.27918 & 1.31 & 0.015263 \\
EP3 & -0.32467 & 0.534 & 0.006204 \\
EP4 & -0.32227 & 1.58 & 0.018321 \\
EP5 & -0.24963 & 0.613 & 0.007003 \\
\hline
\end{tabular}

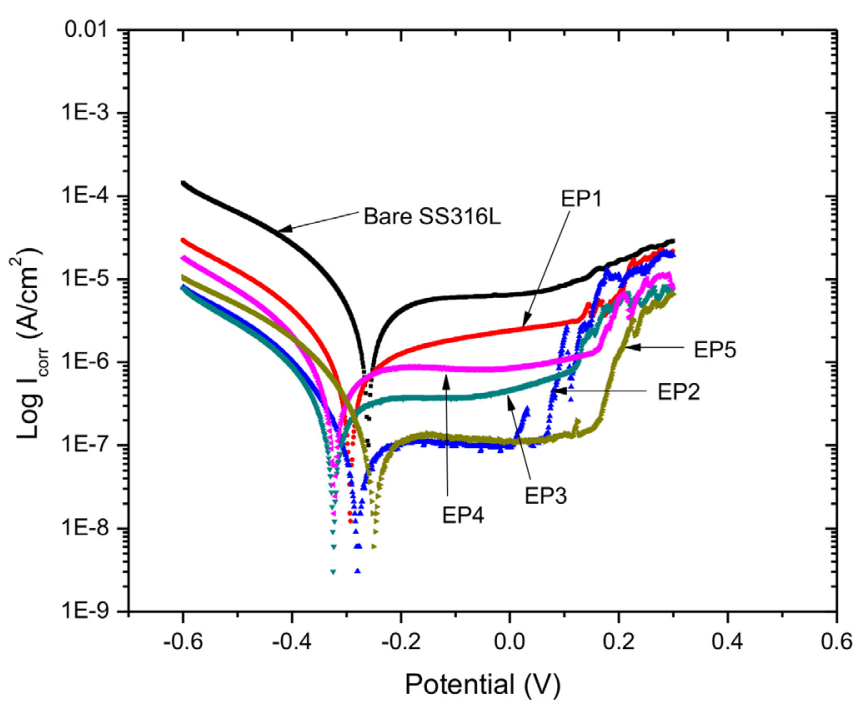

Figure 2: Tafel plot of coated substrates (EP1-EP5) and bare stainless steel 316L 
in corrosion protection of the steel. Even so, it is noted that the $E_{\text {corr }}$ value of the bare stainless steel approaches the positive potential region more than the coated substrates at $-0.26031 \mathrm{~V}$. The corrosion potential, $E_{\text {corr }}$, denotes the resistance to current flow at the surface of a substrate, where a shift of $E_{\text {corr }}$ value towards the positive region shows a passivation reaction that renders the surface inactive to corrosion reaction (Ruhi et al., 2015). The bare stainless steel will form a passivation layer directly upon contact with electrolyte on its surface, which is why the uncoated steel has a higher surface potential. On the other hand, the nanocomposite is embedded in the coating, which means that the electrolyte has to pass through the coating first for the passivation layer to form, which results in low surface potential.

The nanocomposite will form a passivation layer between the coating/metal interface as a result of cathodic reaction of $\mathrm{TiO}_{2}$ and the reaction of PEDOT:PSS with anionic ions (Hou et al., 2013) in the electrolyte that manage to permeate the coating barrier. These reactions will deposit a layer of oxides at the coating/ metal interface that will impede current flow and consequently reducing corrosion rate (Ramya et al., 2010).

As seen from the results in Table 2, the corrosion rate $(\mathrm{mm} / \mathrm{yr})$ decreases as the additive loading increases from $1 \mathrm{wt} . \%$ to $3 \mathrm{wt} . \%$, but starts to increase again at 4 wt.\% additives loading. However, the corrosion rate declines sharply at $5 \mathrm{wt} . \%$ additives down to 0.007003 $\mathrm{mm} / \mathrm{yr}$. It is suggested that the high amount of additives might have increased the percolation network within the coating, hence retarding the permeation of electrons (Ofir et al., 2010). Unfortunately, a higher amount of percolation networks will directly increase the porosity of the particular coating (Beikstein et al., 2003). This is not favourable since it reduces adhesion of coating to the substrate, and lowers the mechanical strength so that the coating fails easily compared to coatings with lower additive content.
Besides that, EP3 has the lowest corrosion rate value at $0.006204 \mathrm{~mm} / \mathrm{yr}$. Plus, EP3 also has the lowest $I_{\text {corr }}$ value at $0.534 \mu \mathrm{A} / \mathrm{cm}^{2}$ compared to EP5 at $0.613 \mu \mathrm{A} / \mathrm{cm}^{2}$ which suggests that the passivation layer formed by EP3 coating at the coating/metal interface was able to impede current flow more efficiently.

\section{Conclusion}

The cytotoxicity assay of the nanocomposite revealed that the compound is biocompatible and is safe for use as anticorrosive additives. As for the anticorrosion properties, taking all parameters into consideration, it can be said that the epoxy coating with the best anticorrosion properties is EP3, with the lowest $I_{\text {corr }}$ and corrosion rate values at $0.534 \mu \mathrm{A} / \mathrm{cm}^{2}$ and $0.006204 \mathrm{~mm} / \mathrm{yr}$; respectively. At 3 wt.\%, the amount of additives is adequate to form a uniform passivation layer at the interface while maintaining good mechanical strength and adhesion of the coating to the substrates.

\section{Acknowledgments}

The authors would like to express the highest gratitude to the Ministry of Higher Education Malaysia for funding this research project under Niche-NRGS grant (Project No. NRGS/2015/53131/14).

\section{References}

Aliofkhazraei, M. (2014). Developments in Corrosion Protection. InTechOpen: Rijeka, Croatia, Chapter 12, 241-270.

Al-Nasiry, S., Geusens, N., Hanssens, M., Luyten, C. \& Pijnenborg, R. (2007). The use of Alamar Blue assay for quantitative analysis of viability, migration and invasion of choriocarcinoma cells. Human Reproduction, 22(5), 1304-1309.

Ates, M., \& Topkaya, E. (2015). Nanocomposite film formations of poluaniline via $\mathrm{TiO}_{2}$, $\mathrm{Ag}$, and $\mathrm{Zn}$, and their corrosion protection properties. Progress in Organic Coatings, 82, 33-40. 
ASTM G31-72(2004), Standard Practice for Laboratory Immersion Corrosion Testing of Metals, ASTM International, West Conshohocken, PA, 2004. Retrieved from www.astm.org.

Benkstein, K. D., N. Kopidakis, N., van de Lagemaat, J. \& Frank, A. J. (2003). Influence of the percolation network geometry on electron transport in dyesensitized titanium dioxide solar cells. The Journal of Physical Chemistry B, 107(31), 7759-7767.

Fabian, E., Landsiedel, R., Ma-Hock, L., Wiench, K., Wohlleben, W. \& van Ravenzwaay, B. (2008). Tissue distribution and toxicity of intravenously administered titanium dioxide nanoparticles in rats. Archives of Toxicology, 82(3), 151-157.

Gajendiran, M., Choi, J., Kim, S. J., Kim, K., Shin, H., Koo, H. J. \& Kim, K. (2017). Conductive biomaterials for tissue engineering applications. Journal of Industrial and Engineering Chemistry, 51, 12-26.

Hamid, R., Rotshteyn, Y., Rabadi, L., Parikh, R. \& Bullock, P. (2004), Comparison of alamar blue and MTT assays for high through-put screening. Toxicology. in Vitro, 18(5), 703710 .

Hempel, F., Ka-Yan Law, J., Nguyen, T. C., Munief, W., Lu, X., Pachauri, V., Susloparova, A., Vu, X. T. \& Ingebrandt, S. (2017). PEDOT:PSS organic electrochemical transistor arrays for extracellular electrophysiological sensing of cardiac cells. Biosensors and. Bioelectronics, 93, 132-138.

Hou, J., Zhu, G., Xu, J. \& Liu, H. (2013). Anticorrosion Performance of Epoxy Coatings Containing Small Amount of Inherently Conducting PEDOT/PSS on Hull Steel in Seawater. Journal of Materials Science \& Technology, 29(7), 678-684.

Ikhmal, W. M. K. W. M., Yasmin, M. Y. N., Fazira, M. F. M., Rafizah, W. A. W., Wan
Nik, W. B. \& Sabri, M. G. M. (2018). Anticorrosion Coating using Olea sp. Leaves Extract. IOP Conference Series: Materials Science and Engineering, 344, 012028.

Koch, G., Varney, J., Thompson, N., Moghissi, O., Gould, M. \& Payer, J. (2016). International measures of prevention, application, and economics of corrosion technologies study, NACE International, Texas, United States of America.

Ofir, S. Dor, L. Grinis, A. Zaban, T. Dittrich and J. Bisquert (2008). Porosity dependence of electron percolation in nanoporous $\mathrm{TiO}_{2}$ layers. The Journal of Chemical Physics, $128,0647031$.

Maria, M. F. F., Ikhmal, W. M. K. W. M., Sabri, M. G. M., Ibrahim, M. S. C. \& Adnan, A. (2018). Identification of functional group present in Andrographis paniculata (kalmegh) leaves by FTIR analysis. IOP Conference Series: Materials Science and Engineering, 440, 012035.

Nur Ain, A. R., Mohd Sabri, M. G., Wan Rafizah, W. A., Nurul Azimah, M. A. \& Wan Nik, W. B. (2018). Effect of ZnO-PEDOT:PSS incorporation in epoxy based coating on corrosion behaviour in immersed condition. ASM Science Journal, Special Issue, 1, 5667.

Nurul Azimah, M. A., Mohd Sabri, M. G., Wan Rafizah, W. A., Wan Nik, W. B., Nurul Huda, A. K., Nur Ain, A. R. \& Nur Afikah, O. (2017). Cytoxicity of $\mathrm{TiO}_{2}$ nanoparticles and effect of incorporation of nanoTiO ${ }_{2}$ PEDOT:PSS composite in PVAc coating on anticorrosive performance. Journal of Sustainability Science and Management, Special Issue, 3, 1-6.

Ramya, S., Anita, T., Shaikh, H. \& Dayal, R. K. (2010). Laser Raman microscopic studies of passive films formed on type 316LN stainless steels during pitting in chloride solution. Corrosion Science, 52, 2114-2121. 
Ruhi, G., Bhandari, H. \& Dhawan, S. K. (2015). Corrosion Resistant Polypyrrole/ Flyash Composite Coatings Designed for Mild Steel Substrate, American Journal of Polymer Science, 5(1A), 18-27.

Safiuddin, M. (2006). Occurrences of corrosion: causes and prevention. BRAC University Journal, 3(1), 71-74.

Vernhes, L., Azzi, M. \& Klemberg-Sapieha, J. E. (2013). Alternatives for hard chromium plating: Nanostructured coatings for severe- service valves. Materials Chemistry and Physics, 140(s2-3), 522-528.

Yazdimamaghani, M., Razavi, M., Mozafari, M., Vashaee, D., Kotturi, H. \& Tayebi L. (2015). Biomineralization and biocompatibility studies of bone conductive scaffolds containing poly $(3,4-$ ethylenedioxythiophene):poly(4-styrene sulfonate) (PEDOT:PSS). Journal of Materials Science: Materials in Medicine, 26(12), 274. 